\title{
Relação entre a presença de cupinzeiros e a degradação de pastagens
}

\author{
Sandra Santana de Lima(1), Bruno José Rodrigues Alves (2), Adriana Maria de Aquino(3), \\ Fábio Martins Mercante ${ }^{(4)}$, Érika Flávia Machado Pinheiro(1), Selenobaldo Alexinaldo Cabral Sant'Anna(1), \\ Segundo Urquiaga( ${ }^{(2)}$ e Robert Michael Boddey ${ }^{(2)}$
}

\begin{abstract}
(1)Universidade Federal Rural do Rio de Janeiro, Departamento de Agronomia e Ciência do Solo, BR 465, Km 7, CEP 23890-000 Seropédica, RJ. E-mail: sandra.biologa@hotmail.com, erika@ufrrj.br, selenobaldo@gmail.com ${ }^{(2)}$ Embrapa Agrobiologia, BR 465, Km 7, CEP 23890-000 Seropédica, RJ. E-mail: bruno@cnpab.embrapa.br, urquiaga@cnpab.embrapa.br, bob@cnpab.embrapa.br (3)Embrapa Agrobiologia, Núcleo de Pesquisa e Treinamento para Agricultores, Avenida Alberto Braune, № 223, Centro, CEP 28613-001 Nova Friburgo, RJ. E-mail: adriana@cnpab.embrapa.br ${ }^{(4)}$ Embrapa Agropecuária Oeste, BR 163, Km 253, Caixa Postal 661, CEP $79804-970$ Dourados, MS. E-mail: mercante@cpao.embrapa.br
\end{abstract}

Resumo - O objetivo deste trabalho foi avaliar indicadores químicos, físicos e biológicos da degradação de pastagens em áreas contrastantes quanto à ocorrência de cupinzeiros. Foram avaliadas as áreas de pastagem com a cultivar Marandu de Urochloa brizantha (Syn. Brachiaria brizantha), quanto à ausência (pasto 1) ou à presença (pasto 2) de cupinzeiros, e área com vegetação nativa de Cerrado. Foram avaliados: granulometria e fertilidade do solo; atividade microbiana do solo; nitrogênio potencialmente mineralizável; produção da gramínea em oferta; liteira existente e depositada no período de 28 dias; e fração leve da matéria orgânica do solo. No pasto 2, os cupinzeiros foram contados e 20 ninhos foram sorteados para coleta e identificação de cupins. Cornitermes cumulans foi a única espécie coletada, com média de 128 ninhos por hectare, tendo ocupado 0,1\% da área útil. Entre os indicadores avaliados, apenas a oferta e a liteira diferiram entre as áreas de pastagens. A maior densidade de cupinzeiros não pode ser relacionada à acidez do solo ou aos outros parâmetros avaliados. A presença de cupinzeiros não é indicador de degradação química e biológica da pastagem e não está associada à alteração na dinâmica de resíduos da parte aérea de capim-marandu.

Termos para indexação: Brachiaria brizantha, Cornitermes cumulans, cupins, montículos, pastagem degradada.

\section{Relationship between the presence of termite mounds and pasture degradation}

\begin{abstract}
The objective of this work was to evaluate chemical, physical and biological indicators of degradation of pastures in areas with contrasting occurrence of termite mounds. Pasture areas with the Marandu cultivar of Urochloa brizantha (Syn. Brachiaria brizantha) were evaluated for the absence (pasture 1) or presence (pasture 2) of termite mounds, and an area of native Cerrado vegetation. The following parameters were evaluated: soil texture and fertility; soil microbial biomass; potentially mineralizable nitrogen; forage on offer; existing litter and litter deposited on the soil surface in 28 days; and free light fraction of soil organic matter. In pasture 2, termite mounds were counted and 20 nests were randomly selected for collection and identification of termites. All active mounds were inhabited by the species Cornitermes cumulans, with a mean of 128 mounds per hectare, occupying $0.1 \%$ of the net area. Among the indicators evaluated, only forage on offer and litter deposited in 28 days differed between pasture areas. The greater density of termite mounds was not related with the higher acidity of the soil or with the other evaluated parameters. The presence of termite mounds is not an indicator of the chemical and biological degradation of the pasture and is associated with the dynamics of aerial residues of Marandu palisadegrass.
\end{abstract}

Index terms: Brachiaria brizantha, Cornitermes cumulans, termites, mounds, degraded pasture.

\section{Introdução}

O Bioma Cerrado, especialmente na região central do Brasil, vem passando por grandes transformações, desde a década de 1970, como nova fronteira agrícola. A existência de uma estação seca e de outra chuvosa, bem definidas, que favorece o planejamento do plantio e da colheita (Siqueira Neto et al., 2009), e as características de relevo plano a suave ondulado, associado a questões de ordem

Pesq. agropec. bras., Brasília, v.46, n.12, p.1699-1706, dez. 2011 
tecnológica, tornaram a região uma das principais frentes de produção agrícola e pecuária no país (Kluthcouski et al., 2004).

Em grande parte da área do Cerrado, houve a retirada da vegetação nativa para a introdução, em larga escala, de gramíneas de origem africana, principalmente as braquiárias (Macedo, 1995). As pastagens são normalmente manejadas em sistema extensivo, com baixo uso de fertilizantes ou, em muitos casos, sem a adição desses insumos. Como resultado, os índices de produtividade dos sistemas pecuários são baixos e os declínios de produção ao longo do tempo são evidentes (Miranda, 2001). Atualmente, a monocultura de pastagens atinge área de aproximadamente 54 milhões de hectares, na região dos Cerrados (Sano, 2008). Porém, é provável que cerca de 60 a $80 \%$ dessa área esteja em processo de degradação (Miranda, 2001). De acordo com Macedo (1995), as pastagens em degradação têm baixa capacidade de suporte e se caracterizam por reduzida cobertura vegetal e pequeno número de plantas novas - provenientes da ressemeadura natural -, com áreas invadidas por plantas não palatáveis e densamente ocupadas por ninhos epígeos de cupins.

Entre os fatores mais importantes relacionados à degradação das pastagens, destacam-se o manejo animal inadequado e a falta de reposição de nutrientes. Assim, o processo de degradação tem sido acelerado pela lotação animal excessiva, sem os ajustes para a adequada capacidade de suporte, e pela ausência de adubação de manutenção (Macedo, 2009). Segundo Oliveira et al. (2004), N e P são os nutrientes que mais limitam o crescimento de braquiárias em solos de cerrado, dos quais o primeiro seria o mais relevante. De acordo com Boddey et al. (2004), as perdas de $\mathrm{N}$ associadas às excretas dos bovinos seria uma das hipóteses para explicar o início do processo de degradação.

A queda na produção de massa verde é um dos principais sinais de degradação, além de outras modificações menos perceptíveis, como alterações físicas, químicas e da fauna do solo (Rodrigues et al., 2000; Boddey et al., 2004). Brossard \& Barcellos (2005) relataram que a fauna do solo não contribui para o processo de degradação, mas que ocorre adequação temporal entre a idade da pastagem e a adaptação das populações de macrofauna de invertebrados à oferta trófica do ambiente de pastagem.
Alguns autores citam a presença de ninhos de termitas (cupins) como sinal do processo de degradação em pastagens (Macedo, 1995; Aquino et al., 2008). Santos et al. (2007) caracterizaram os estágios de degradação em inicial e moderado, ao considerar a menor e a maior quantidade de ninhos nas áreas. Esse número tende a aumentar em áreas menos sujeitas à mecanização; portanto, pastagens mais velhas normalmente apresentam infestações mais elevadas (Valério, 2006), sem necessariamente estar em processo de perda de vigor.

Embora a presença de ninhos de cupins (cupinzeiros) esteja associada à degradação da pastagem ou mesmo a processos como diminuição da fertilidade e, especialmente, aumento da acidez do solo, não é claro se o aparecimento dos ninhos é consequência da degradação ou fenômeno natural induzido pela falta de controle do inseto.

O objetivo deste trabalho foi avaliar indicadores químicos, físicos e biológicos da degradação de pastagens em áreas contrastantes quanto à ocorrência de cupinzeiros.

\section{Material e Métodos}

Os experimentos foram realizados na Fazenda Campana $\left(22^{\circ} 16^{\prime} 29^{\prime \prime} \mathrm{S}\right.$ e $54^{\circ} 48^{\prime} 57^{\prime \prime} \mathrm{W}$, a $353 \mathrm{~m}$ de altitude), no Município de Rio Brilhante, ao sudoeste de Mato Grosso do Sul, região agropecuária e sucroalcooleira, da microrregião da Grande Dourados, a $161 \mathrm{~km}$ da capital, Campo Grande. A região avaliada está localizada no Bioma Cerrado, com fitofisionomia de cerradão, e apresenta extensas áreas de pastagens que cobrem aproximadamente $80 \%$ da área total do município.

O clima predominante é o tropical, que se apresenta claramente dividido em duas estações: inverno seco e verão úmido, chuvoso e quente. A temperatura média anual é de $20^{\circ} \mathrm{C}$, com variação da média mensal entre 18 e $22^{\circ} \mathrm{C}$. A precipitação nos anos de coleta, em 2009 e 2010, foi de 2.272 e $1.875 \mathrm{~mm}$, respectivamente. As áreas selecionadas apresentavam histórico semelhante: antes de 1989, eram utilizadas como pasto de Panicum maximum, que degradou e depois foi dominado pela grama mato-grosso, também conhecida por grama-batatais (Paspalum notatum). De 1989 a 1991, a área foi cultivada com soja e, em seguida, com Urochloa brizantha (Syn. Brachiaria 
brizantha) (Shirasuna, 2010), tendo sido dividida em sete piquetes de aproximadamente 60 ha. Em cada invernada, o gado pasteja por sete a oito dias e, após esse período, é conduzido a outro piquete. Desde a sua implantação, a pastagem foi mantida sem nenhuma adição de fertilizante. Apesar disso, a pastagem não apresentava sinais de degradação do solo.

Foram selecionadas duas áreas de pasto, em diferentes piquetes, e umaárea em fragmento de cerradão próximo, para análise. Para a escolha das áreas, considerou-se a proximidade e a similaridade topográfica, o manejo e a idade, e o contraste na ocorrência de ninhos de cupins. Foi chamado de pasto 1 o piquete que não apresentava ninhos epígeos, e de pasto 2 , o piquete com alta densidade de ninhos. A área de cerradão selecionada também estava localizada dentro de um piquete, ao lado do pasto 2, e era eventualmente utilizada como abrigo para o gado. As áreas eram justapostas, e os pontos de coleta de cada uma estavam distantes aproximadamente $1.500 \mathrm{~m}$, entre si.

Em cada área de pastagem, foram delimitados 4 ha para a avaliação dos indicadores de degradação, de acordo com Oliveira et al. (2004). Para facilitar as amostragens, as áreas foram divididas em quatro parcelas de 1 ha. Posteriormente, sorteou-se uma parcela do pasto 2 para contagem, avaliação da vitalidade (presença de cupins) e medição da altura e da circunferência de todos os ninhos. A área ocupada pelos ninhos foi calculada a partir do valor da circunferência, tendo-se calculado o raio $(\mathrm{r}=\mathrm{c} / 2 \pi)$ e a área da base $\left(\mathrm{A}=\pi \times \mathrm{r}^{2}\right)$. Em seguida, foram sorteados 20 ninhos para coleta de cupins. Os cupins foram conservados em álcool a $80 \%$, e os gêneros e as espécies foram identificados no laboratório de Isoptera do Museu de Zoologia da Universidade de São Paulo, onde o material foi depositado.

O solo foi amostrado em abril de 2010, tendo-se coletado três amostras compostas, a partir de cinco amostras simples, nas camadas de $0-5$ e de $5-15 \mathrm{~cm}$, com uso de trado holandês, de cada uma das quatro parcelas de 1 ha. Também foram feitas amostragens de solo na área de cerradão, mas os resultados não foram comparados aos das pastagens, por ser considerado solo sem interferência antrópica.

Foram avaliados os parâmetros: granulometria e fertilidade do solo; atividade microbiana do solo; nitrogênio potencialmente mineralizável; produção da gramínea em oferta; liteira existente e depositada no período de 28 dias; e fração leve da matéria orgânica do solo.

Para a análise granulométrica, as percentagens das frações areia, silte e argila foram avaliadas por meio de peneiramento, seguido do método da pipeta (Claessen, 1997).

Quanto à fertilidade, para a caracterização química do solo, foram determinados: $\mathrm{pH}$ em água; complexo sortivo (Al, Ca, Mg, Al+H, K e Na); P (Mehlich-1); e capacidade de troca catiônica (CTC), de acordo com Claessen (1997).

A determinação do carbono orgânico total foi realizada por via seca a partir de $250 \mathrm{mg}$ de amostra de solo por oxidação a $900^{\circ} \mathrm{C}$, tendo-se utilizado analisador elementar de carbono TOC-V, (Shimadzu, Kyoto, Japão), no Laboratório de Solos, Plantas e Corretivos da Embrapa Agropecuária Oeste. Para os cálculos, utilizou-se curva de calibração obtida com padrão de glicose. O carbono da biomassa microbiana (C-BMS) foi avaliado pelo método da fumigação-extração, conforme Vance et al. (1987). A respiração basal $\left(\mathrm{C}-\mathrm{CO}_{2}\right)$, obtida pela incubação das amostras com captura de $\mathrm{CO}_{2}$, em $\mathrm{NaOH}$, durante sete dias, foi determinada pela adaptação do método da fumigação-incubação, segundo Jenkinson \& Powlson (1976). O quociente metabólico $\left(\mathrm{qCO}_{2}\right)$, foi definido por meio da relação entre a respiração e o $\mathrm{C}$ da biomassa microbiana (C-CO $\mathrm{CO}_{2} / \mathrm{C}$-BMS), de acordo com Anderson \& Domsch (1990). Os índices da qualidade nutricional da matéria orgânica foram expressos pelo quociente microbiano (qMIC), definido pela relação entre o $\mathrm{C}$ da biomassa microbiana e o $\mathrm{C}$ orgânico total do solo (C-BMS/C-orgânico total). O conteúdo de matéria orgânica (MO) foi determinado conforme Claessen (1997). Todas as determinações foram efetuadas em triplicatas.

A mineralização em condições anaeróbicas foi adaptada de Waring \& Bremner (1964), para determinação do nitrogênio potencialmente mineralizável. Foram pesados $10 \mathrm{~g}$ de TFSA de cada amostra e, posteriormente, foram adicionados $2,5 \mathrm{~mL}$ de água destilada. Os tubos foram agitados para eliminação de possíveis bolhas de ar presas no solo e, após agitação, foram tapados com filme plástico (parafilm) e colocados em incubação, em estufa a $40^{\circ} \mathrm{C}$, por sete dias. Após o período de incubação, o amônio foi extraído com $\mathrm{KCl} 2 \mathrm{~mol} \mathrm{~L}^{-1} \mathrm{e}$ analisado por colorimetria (Alves, 1994).

Pesq. agropec. bras., Brasília, v.46, n.12, p.1699-1706, dez. 2011 
Para determinação da oferta de forragem, da liteira existente e da deposição de liteira, a quantidade da gramínea em oferta foi quantificada por meio do corte das plantas a $10 \mathrm{~cm}$ do solo, em área de $1 \mathrm{x} 1 \mathrm{~m}$, com quatro repetições por hectare. Antes da pesagem, o material foi seco em estufa com ventilação forçada por 72 horas, a $65^{\circ} \mathrm{C}$. A amostragem da liteira foi realizada a partir de um quadrado com $1 \times 1 \mathrm{~m}$, tendose obtido quatro amostras por hectare. A liteira foi totalmente removida manualmente, lavada e, em seguida, submetida ao mesmo procedimento de secagem e pesagem do material em oferta. Após 28 dias, fez-se a coleta da liteira depositada na mesma área (Oliveira et al., 2004).

A análise da fração leve da matéria orgânica do solo foi realizada por meio do fracionamento por densidade, com solução de iodeto de sódio (Sohi et al., 2001). A densidade da solução foi de $1,2 \mathrm{~g} \mathrm{~cm}^{-3}$, de acordo com Oliveira et al. (2004). A partir de uma pequena alíquota de TFSA, foi determinado o teor de umidade. Posteriormente, $5 \mathrm{~g}$ de TFSA foram pesados e transferidos para frascos de centrífuga de $50 \mathrm{~mL}$, tendo-se adicionado $35 \mathrm{~mL}$ da solução de iodeto. A fração leve foi cuidadosamente lavada com água destilada para eliminar o excesso de $\mathrm{NaI}$ presente na fração e no filtro usado na separação. Em seguida, a fração orgânica foi secada a $65^{\circ} \mathrm{C}$ e pesada.

As análises granulométricas, de fertilidade e de carbono da biomassa microbiana, foram realizadas na Embrapa Agropecuária Oeste. A análise da fração leve da matéria orgânica foi realizada no laboratório de Física do Solo da Universidade Federal Rural do Rio de Janeiro, enquanto a análise do $\mathrm{N}$ potencialmente mineralizável foi realizada na Embrapa Agrobiologia, ambas no Município de Seropédica, RJ.

Utilizou-se o delineamento inteiramente casualizado. Os dados foram submetidos aos testes de Lilliefors e de Cochran e Bartllet, para verificar a normalidade e a homogeneidade das variâncias, respectivamente. Os dados que não atenderam às premissas da análise de variância foram submetidos à análise não paramétrica, e as médias foram comparadas pelo teste de Wilcoxon, a 5\% de probabilidade, pelo programa SAEG 5.0 (Ribeiro Júnior, 2001). As variáveis que atenderam pelo menos uma premissa foram submetidas à análise de variância, e as médias foram comparadas pelo teste $\mathrm{t}$
(Bonferroni), a 5\% de probabilidade, com uso do programa Sisvar (Ferreira, 2008).

\section{Resultados e Discussão}

Por meio da identificação taxonômica, verificou-se que todos os ninhos eram habitados por Cornitermes cumulans. De acordo com Redford (1984), essa é uma das espécies mais comuns em áreas de pastagens no Cerrado e é considerada espécie chave na região, pois seus ninhos podem abrigar uma série de outras espécies de cupins e apresentam teor de nutrientes superior ao do solo adjacente. Embora seja muito comum encontrar outras espécies de cupins em ninhos de Cornitermes, isso não foi observado no presente trabalho. Em Goiânia, Cunha et al. (2010) relataram que ninhos de Cornitermes snyderi e de Syntermes grandis abrigavam de 8 a 14 espécies, em um mesmo cupinzeiro.

Foi verificada média de 128,5 ninhos por hectare, e $89 \%$ destes ninhos estavam ativos. A média de ninhos observada no presente trabalho foi superior à de 73 ninhos por hectare obtida por Czepak et al. (2003), em 133 municípios goianos. Cunha et al. (2010) verificaram média de 182 ninhos por hectare, enquanto Oliveira et al. (2011) relataram, no Cerrado do Planalto Central, número médio de 408 ninhos por hectare e maior número de cupinzeiros em pastagem com dez anos (672 ninhos).

No presente trabalho, a área ocupada pelos ninhos foi de apenas $0,1 \%$, sem efeito significativo na área útil para pastejo, como observado por Czepak et al. (2003), Cunha et al. (2010) e Oliveira et al. (2011).

Quanto à análise granulométrica, não houve diferenças significativas entre os solos dessas áreas (Tabela 1), o que traz maior segurança na comparação dos resultados.

Não foram observadas diferenças entre os valores de $\mathrm{pH}, \mathrm{Al}$ e $\mathrm{H}+\mathrm{Al}$ entre as duas áreas (Tabela 2), o que contraria a ideia de que a presença dos cupinzeiros em pastagens é relacionada à maior acidez do solo. A concentração de $\mathrm{P}$ nos solos, importante para a formação de pastagens em solos da região do Cerrado (Vilela et al., 1998), também não diferiu entre as pastagens, e os maiores valores foram observados na camada de $0-5 \mathrm{~cm}$. Os valores observados no presente trabalho foram superiores aos de Oliveira et al. (2004). Estes autores verificaram que, na maioria das pastagens avaliadas, a concentração de $\mathrm{P}$ no solo encontrava- 
se abaixo do limite de detecção $\left(1 \mathrm{mg} \mathrm{dm}^{-3}\right)$ pela metodologia utilizada.

Não foram observadas diferenças significativas entre os demais atributos químicos do solo entre as pastagens, em ambas as profundidades. De acordo com Oliveira et al. (2004), os resultados da fertilidade do solo não são adequados como indicadores da produtividade das pastagens. Os resultados obtidos no presente trabalho são indicativos de que, para essas áreas, o aumento de ninhos de cupins nas pastagens não está relacionado às características químicas do solo (Tabela 2), inclusive à acidez do solo.

A concentração de $\mathrm{C}$ da biomassa microbiana foi similar entre as pastagens, bem como a respiração basal, o quociente metabólico e o quociente microbiano, em ambas as profundidades de amostragem do solo (Tabela 3). A biomassa microbiana pode ser indicador de perda de produtividade da pastagem. Luizão et al. (1999) observaram diferenças entre pastagens recentemente implantadas e pastagens velhas, em solo da Amazônia, o que pode ser atribuído à redução da

Tabela 1. Granulometria do solo na profundidade de $0-5 \mathrm{~cm}$, em áreas de pastagens de capim-marandu ${ }^{(1)}$.

\begin{tabular}{lccc}
\hline Tratamento & Areia & $\begin{array}{c}\text { Silte } \\
\left(\mathrm{g} \mathrm{kg}^{-1}\right)\end{array}$ & $\begin{array}{c}\text { Argila } \\
\text { Pasto 1 }\end{array}$ \\
Pasto 2 & $622 \mathrm{a}$ & $94 \mathrm{a}$ & $283 \mathrm{a}$ \\
Cerrado $^{(2)}$ & $584 \mathrm{a}$ & $94 \mathrm{a}$ & $321 \mathrm{a}$ \\
\hline
\end{tabular}

${ }^{(1)}$ Médias seguidas de letras iguais, na coluna, não diferem entre si pelo teste de Bonferroni, a $5 \%$ de probabilidade. ${ }^{(2)} \mathrm{Os}$ resultados não foram comparados pelo teste, pois o cerrado difere das áreas de pasto. Pasto 1, sem ninhos de térmita; Pasto 2, com alta densidade de ninhos de termitas. disponibilidade de $\mathrm{N}$ no solo. No presente trabalho, ambas as pastagens apresentavam reservatórios lábeis de $\mathrm{N}$ semelhantes, representado pelo potencial de mineralização de N (Figura 1). Esses autores observaram decréscimo significativo da quantidade de $\mathrm{C}$ no solo, na pastagem mais antiga, o que não foi confirmado no presente trabalho, com base nos resultados de matéria orgânica do solo. As pastagens mostram-se muito similares para indicadores microbianos e de $\mathrm{C}$ no solo, apesar das diferenças no número de cupinzeiros.

O material vegetal em oferta apresentou diferença significativa entre as duas pastagens, e a quantidade de forragem no pasto 1 superou a observada no pasto 2 , no momento da amostragem (Figura 2). Santos et al. (2007) avaliaram pastagens com diferentes idades na região de Goiânia, GO, e observaram quantidades inferiores às obtidas no presente trabalho, em que uma pastagem de capimmarandu de nove anos apresentava $1.280 \mathrm{~kg} \mathrm{ha}^{-1} \mathrm{de}$ material em oferta. Embora os valores verificados tenham diferido significativamente entre si, esses dados não podem ser considerados suficientemente seguros para confirmar que o pasto 1 é mais produtivo que o pasto 2 , em virtude da rotação do gado nas áreas, o que pode ter influenciado na quantidade de material em oferta, no momento da amostragem.

Não foi observada diferença entre as pastagens em relação à quantidade existente de liteira sobre o solo (Figura 2). No entanto, a liteira depositada após 28 dias no pasto 1 foi superior à do pasto 2 , no mesmo período. A maior quantidade de liteira depositada sobre o solo indica maior aporte de matéria orgânica,

Tabela 2. Características químicas do solo nas profundidades de $0-5$ e de $5-15 \mathrm{~cm}$, em áreas de pastagens de capimmarandu ${ }^{(1)}$.

\begin{tabular}{|c|c|c|c|c|c|c|c|c|c|c|c|c|}
\hline Tratamento & $\begin{array}{c}\mathrm{pH} \\
\mathrm{em} \mathrm{H}_{2} \mathrm{O}\end{array}$ & $\begin{array}{c}\mathrm{pH} \\
\mathrm{em} \mathrm{CaCl}_{2}\end{array}$ & $\begin{array}{c}\mathrm{P} \\
\left(\mathrm{mg} \mathrm{dm}^{-3}\right)\end{array}$ & $\mathrm{K}^{+}$ & $\mathrm{Al}^{+3}$ & $\mathrm{H}+\mathrm{Al}^{+3}$ & $\begin{array}{l}\mathrm{Ca}^{+2} \\
--(\mathrm{cn}\end{array}$ & $\begin{array}{c}\mathrm{Mg}^{+2} \\
\left.\mathrm{dm}^{-3}\right)-\end{array}$ & SB & CTC & CTCe & $\begin{array}{c}\mathrm{V} \\
(\%)\end{array}$ \\
\hline & \multicolumn{12}{|c|}{ Camada de $0-5 \mathrm{~cm}$} \\
\hline Pasto 1 & $5,8 \mathrm{a}$ & $5,1 \mathrm{a}$ & $1,8 \mathrm{a}$ & $0,3 a$ & $0,0 \mathrm{a}$ & $4,0 \mathrm{a}$ & $3,5 \mathrm{a}$ & $1,9 \mathrm{a}$ & $5,7 \mathrm{a}$ & $9,8 \mathrm{a}$ & $5,7 \mathrm{a}$ & $58,7 \mathrm{a}$ \\
\hline Pasto 2 & $5,9 \mathrm{a}$ & $5,2 \mathrm{a}$ & $1,4 a$ & $0,7 \mathrm{a}$ & $0,0 \mathrm{a}$ & $3,9 a$ & $3,2 \mathrm{a}$ & $2,2 \mathrm{a}$ & $6,1 \mathrm{a}$ & $9,0 \mathrm{a}$ & $6,1 \mathrm{a}$ & $60,1 \mathrm{a}$ \\
\hline \multirow[t]{2}{*}{ Cerradão $^{(2)}$} & 6,9 & 6,4 & 3,2 & 0,6 & 0,0 & 2,1 & 9,8 & 3,6 & 13,9 & 16,0 & 13,9 & 86,5 \\
\hline & \multicolumn{12}{|c|}{ Camada de $5-15 \mathrm{~cm}$} \\
\hline Pasto 1 & $5,6 \mathrm{a}$ & $4,9 \mathrm{a}$ & $0,9 \mathrm{a}$ & $0,2 \mathrm{a}$ & $0,0 a^{*}$ & $4,0 \mathrm{a}$ & $2,9 \mathrm{a}$ & $1,1 \mathrm{a}$ & $4,2 \mathrm{a}$ & $8,2 \mathrm{a}$ & $4,2 \mathrm{a}$ & $51,4 \mathrm{a}$ \\
\hline Pasto 2 & $5,6 a$ & $4,9 \mathrm{a}$ & $0,8 \mathrm{a}$ & $0,4 \mathrm{a}$ & $0,1 \mathrm{a} *$ & $4,3 a$ & $2,6 a$ & $1,1 \mathrm{a}$ & $4,1 \mathrm{a}$ & $8,4 \mathrm{a}$ & $4,2 \mathrm{a}$ & $48,3 a$ \\
\hline Cerradão $^{(2)}$ & 6,3 & 5,7 & 1,0 & 0,4 & 0,0 & 2,8 & 3,8 & 2,2 & 6,4 & 9,2 & 6,4 & 68,9 \\
\hline
\end{tabular}

${ }^{(1)}$ Médias seguidas de letras iguais, na coluna, não diferem entre si pelo teste de Bonferroni, a $5 \%$ de probabilidade. ${ }^{(2)}$ Os resultados não foram comparados pelo teste, pois o Cerrado difere das áreas de pasto. Pasto 1 , sem ninhos de térmita; Pasto 2 , com alta densidade de ninhos de termitas. * Significativo pelo teste não paramétrico de Wilcoxon, a $5 \%$ de probabilidade. 
além de melhores condições para a biota do solo em relação à disponibilidade de alimento e ao microclima. A quantidade depositada em 28 dias no pasto 1 $\left(1.462 \mathrm{~kg} \mathrm{ha}^{-1}\right)$ foi superior à verificada por Santos et al. (2007), em áreas com capim-marandu de nove anos (109 $\left.\mathrm{kg} \mathrm{ha}^{-1}\right)$ e com capim-basilisk de 20 anos (232 kg ha $\left.{ }^{-1}\right)$.

Os resultados da análise da fração leve da matéria orgânica do solo, para ambas as profundidades analisadas, não diferiram significativamente entre os pastos (Tabela 3). Esses resultados contrariam o observado na deposição da liteira, pois se esperava que a maior deposição levasse à maior quantidade da fração leve da matéria orgânica (Oliveira et al., 2004). Portanto, a avaliação do comportamento da liteira em um único período do ano pode ser insuficiente como indicador de qualidade da pastagem.

Embora seja possível, não há evidência concreta de que a existência de cupinzeiros em uma das áreas seja indicação de degradação da pastagem (Santos et al., 2007). Os resultados obtidos são indicativos de que, em ambas as áreas avaliadas, não houve mudanças de fertilidade do solo. Já os indicadores de dinâmica da matéria orgânica do solo, sugerem condições similares entre as pastagens, o que permite concluir que a densidade de cupins não estaria relacionada ao processo de degradação.

Tabela 3. Carbono da biomassa microbiana (C-BMS), respiração basal $\left(\mathrm{C}-\mathrm{CO}_{2}\right)$, quociente metabólico $\left(\mathrm{qCO}_{2}\right)$, quociente microbiano (qMIC), matéria orgânica (MO) e fração leve da MO (FLMO), em solo seco, nas camadas de $0-5$ e de $5-15 \mathrm{~cm}$, em áreas de pastagens de capimmarandu $u^{(1)}$.

\begin{tabular}{|c|c|c|c|c|c|c|}
\hline Tratamento & $\begin{array}{l}\text { C-BMS } \\
-----(\mu\end{array}$ & $\begin{array}{l}\mathrm{C}-\mathrm{CO}_{2} \\
\left.\mathrm{~g}^{-1}\right)-\end{array}$ & $\mathrm{qCO}_{2}$ & $\begin{array}{c}\text { qMIC } \\
(\%)\end{array}$ & $\begin{array}{l}\text { MO } \\
----(g\end{array}$ & $\begin{array}{l}\text { FLMO } \\
\left.g^{-1}\right) \text {--- }\end{array}$ \\
\hline & \multicolumn{6}{|c|}{ Camada de $0-5 \mathrm{~cm}$} \\
\hline Pasto 1 & $301,9 a$ & $27,0 \mathrm{a}$ & $41,8 \mathrm{a}$ & $1,38 \mathrm{a}$ & $40,0 \mathrm{a}$ & $1,93 \mathrm{a}$ \\
\hline Pasto 2 & $284,9 a$ & $25,8 \mathrm{a}$ & $44,1 \mathrm{a}$ & $1,17 \mathrm{a}$ & $41,2 \mathrm{a}$ & $2,21 \mathrm{a}$ \\
\hline \multirow[t]{2}{*}{ Cerradão $^{(2)}$} & 457,0 & 54,0 & 53,8 & 1,35 & 67,9 & 8,14 \\
\hline & \multicolumn{6}{|c|}{ Camada de $5-15 \mathrm{~cm}$} \\
\hline Pasto 1 & $130,9 a$ & $18,9 \mathrm{a}$ & $95,1 \mathrm{a}$ & $0,97 \mathrm{a}$ & $22,7 b$ & $1,22 \mathrm{a}$ \\
\hline Pasto 2 & $130,4 a$ & $17,7 \mathrm{a}$ & $72,8 \mathrm{a}$ & $0,78 \mathrm{a}$ & $28,0 \mathrm{a}$ & $1,41 \mathrm{a}$ \\
\hline Cerradão $^{(2)}$ & 205,8 & 26,5 & 56,1 & $1,64 \mathrm{a}$ & 22,5 & 2,57 \\
\hline
\end{tabular}

${ }^{(1)}$ Médias seguidas de letras iguais, na coluna, não diferem entre si pelo teste de Bonferroni, a $5 \%$ de probabilidade. ${ }^{(2)} \mathrm{Os}$ resultados não foram comparados pelo teste, pois o Cerrado difere das áreas de pasto. Pasto 1, sem ninhos de térmita; pasto 2, com alta densidade de ninhos de térmitas.

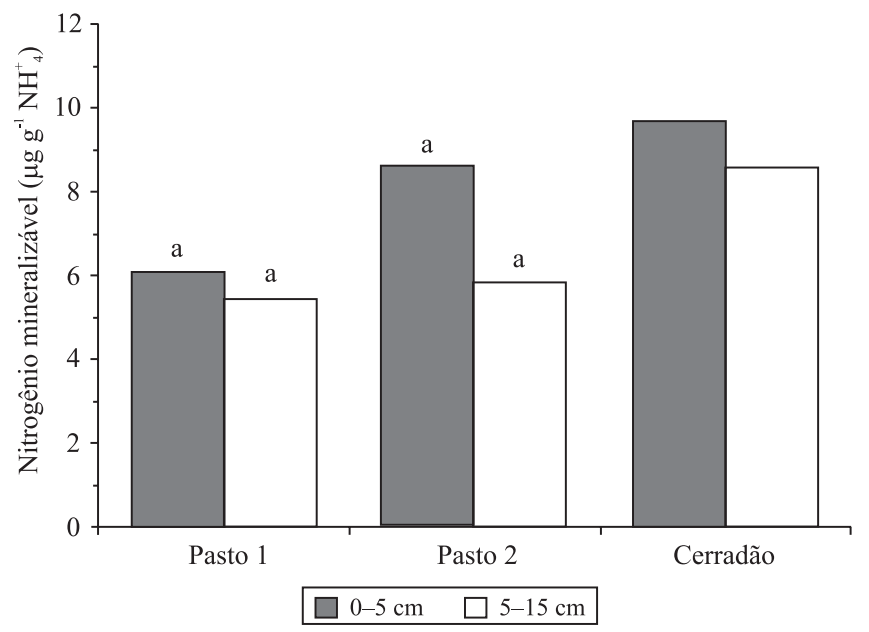

Figura 1. Nitrogênio potencialmente mineralizável nas profundidades de $0-5$ e de $5-15 \mathrm{~cm}$, em áreas de pastagens de capim-marandu. Pasto 1, sem ninhos de termitas; pasto 2 , com alta densidade de ninhos de termitas.

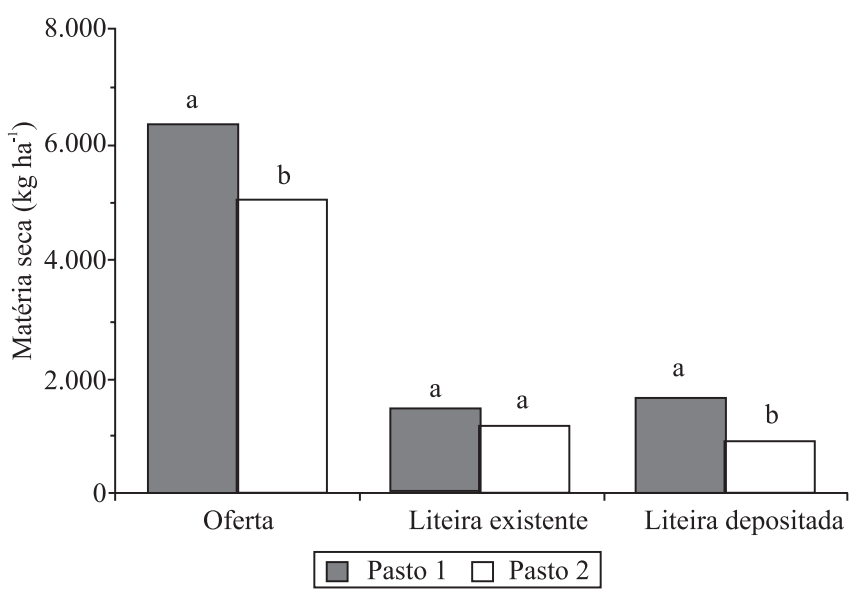

Figura 2. Produção de matéria seca de forragem, liteira existente e depositada após 28 dias em áreas de pastagens de capim-marandu. Pasto 1, sem ninhos de termitas; pasto 2, com alta densidade de ninhos de termitas.

\section{Conclusão}

A presença de ninhos epígeos de cupins não é indicador de degradação química e biológica da pastagem e não está associada à alteração na dinâmica de resíduos da parte aérea de capim-marandu. 


\section{Agradecimentos}

À Coordenação de Aperfeiçoamento de Pessoal de Nível Superior, pela concessão de bolsa; ao Conselho Nacional de Desenvolvimento Científico e Tecnológico, pelo apoio financeiro; e ao Sr. Arthur Coelho Barbosa, proprietário da Fazenda Campana, pela concessão das áreas de avaliação e pelo apoio logístico durante a realização das avaliações.

\section{Referências}

ALVES, B.J.R. Avaliação da mineralização do $\mathbf{N}$ do solo in situ . 1994. 177p. Dissertação (Mestrado) - Universidade Federal Rural do Rio de Janeiro, Itaguaí.

ANDERSON, T.H.; DOMSCH, K.H. Application of ecophysiological quotients $\left(q \mathrm{CO}_{2}\right.$ and $\left.q \mathrm{D}\right)$ on microbial biomasses from soils of different cropping histories. Soil Biology and Biochemistry, v.22, p.251-255, 1990.

AQUINO, A.M.; CORREIA, M.E.F.; ALVES, M.V. Diversidade da macrofauna edáfica no Brasil. In: MOREIRA, F.M.S.; SIQUEIRA, J.O.; BRUSSAARD, L. (Ed.). (Org.). Diversidade do solo em ecossistemas brasileiros. Lavras: UFLA, 2008. p.143-170.

BODDEY, R.M.; MACEDO, R.; TARRÉ, R.M.; FERREIRA, E.; OLIVEIRA, O.C. de; REZENDE, C. de P.; CANTARUTTI, R.B.; PEREIRA, J.M.; ALVES, B.J.R.; URQUIAGA, S. Nitrogen cycling in Brachiaria pastures: the key to understanding the process of pasture decline. Agriculture, Ecosystems and Environment, v.103, p.389-403, 2004.

BROSSARD, M.; BARCELLOS, A. de O. Conversão do cerrado em pastagens cultivadas e funcionamento de Latossolos. Cadernos de Ciência e Tecnologia, v.22, p.153-168, 2005.

CLAESSEN, M.E.C. (Org.). Manual de métodos de análise de solo. 2.ed. rev. atual. Rio de Janeiro: Embrapa-CNPS, 1997. 212p. (Embrapa-CNPS. Documentos, 1).

CUNHA, H.F. da; MORAIS, P.P.A.M. Relação espécie-área em cupinzeiros de pastagem, Goiânia-GO, Brasil. EntomoBrasilis, v.3, p.60-63, 2010.

CZEPAK, C.; ARAÚJO, E.A. de; FERNANDES, P.M. Ocorrência de espécies de cupins de montículo em pastagens no Estado de Goiás. Pesquisa Agropecuária Tropical, v.33, p.35-38, 2003.

FERREIRA, D.F. SISVAR: um programa para análises e ensino de estatística. Revista Symposium, v.6, p.36-41, 2008.

JENKINSON, D.S.; POWLSON, D.S. The effects of biocidal treatments on metabolism in soil. V. A method for measuring soil biomass. Soil Biology and Biochemistry, v.8, p.209-213, 1976.

KLUTHCOUSKI, J.; AIDAR, H.; STONE, L.F.; COBUCCI, T. Integração lavoura-pecuária e o manejo de plantas daninhas. Informações Agronômicas, n.106, p.1-20, 2004. Encarte técnico.

LUIZÃO, R.C.C.; COSTA E.S.; LUIZÃO, F.J. Mudanças na biomassa microbiana e nas transformações de nitrogênio do solo em uma seqüência de idades de pastagens após derruba e queima da floresta na Amazônia Central. Acta Amazônica, v.29, p.43-56, 1999.

MACEDO, M.C.M. Integração lavoura-pecuária: o estado da arte e inovações tecnológicas. Revista Brasileira de Zootecnia, v.38, p.133-146, 2009. Suplemento especial.

MACEDO, M.C.M. Pastagens no ecossistema Cerrados: pesquisa para o desenvolvimento sustentável. In: SIMPÓSIO SOBRE PASTAGENS NOS ECOSSISTEMAS BRASILEIRO: PESQUISAS PARA O DESENVOLVIMENTO SUSTENTÁVEL, 1995, Brasília. Anais. Brasília: Sociedade Brasileira de Zootecnia, 1995. p.28-62.

MIRANDA, C.H.B. Ciclagem de nutrientes em pastagens com vistas à sustentabilidade do sistema. In: HERRERO, M.; RAMÍREZ, A. (Ed.). Manejo y evaluación de pasturas tropicales. Santa Cruz: CIAT, 2001. p.95-108.

OLIVEIRA, M.I.L. de; BRUNET, D.; MITJA, D.; CARDOSO, W.S.; BENITO, N.P.; GUIMARÃES, M.F.; BROSSARD, M. Incidence of epigeal nest-building termites in Brachiaria pastures in the Cerrado. Acta Scientiarum. Agronomy, v.33, p.181-185, 2011.

OLIVEIRA, O.C. de; OLIVEIRA, I.P. de; ALVES, B.J.R.; URQUIAGA, S.; BODDEY, R.M. Chemical and biological indicators of decline/degradation of Brachiaria pastures in the Brazilian Cerrado. Agriculture, Ecosystems and Environment, v.103, p.289-300, 2004.

REDFORD, K.H. The termitaria of Cornitermes cumulans (Isoptera: Termitidae) and their role in determining a potential keystone species. Biotropica, v.16, p.112-119, 1984.

RIBEIRO JÚNIOR, J. I. Análises estatísticas no SAEG. Viçosa: UFV, 2001. 301p.

RODRIGUES, L.R. de A.; QUADROS, D.G.; RAMOS, A.K.B. Recuperação de pastagens degradadas. In: SIMPÓSIO PECUÁRIA 2000 - PERSPECTIVAS PARA O III MILÊNIO, 1., 2000, Pirassununga. Anais. Pirassununga: USP, 2000. p.1-17.

SANO, E.E.; ROSA, R.; BRITO, J.L.S.; FERREIRA, L.G. Mapeamento semidetalhado do uso da terra do Bioma Cerrado. Pesquisa Agropecuária Brasileira, v.43, p.153-156, 2008.

SANTOS, R.S.M. dos; OLIVEIRA, I.P. de; MORAIS, R.F. de; URQUIAGA, S.C.; BODDEY, R.M.; ALVES, B.J.R. Componentes da parte aérea e raízes de pastagens de Brachiaria spp. em diferentes idades após a reforma, como indicadores de produtividade em ambiente de Cerrado. Pesquisa Agropecuária Tropical, v.37, p.119-124, 2007.

SHIRASUNA, R.T. Lista de espécies da flora do Brasil: Urochloa humidicola (Rendle) Morrone \& Zuloaga. Rio de Janeiro: Jardim Botânico, 2010. Disponível em: <http://floradobrasil.jbrj.gov. br/2010/FB087091/>/. Acesso em: 21 jun. 2010.

SIQUEIRA NETO, M.; PICCOLO, M. de C.; SCOPEL, E.; COSTA JUNIOR, C. da; CERRI, C.C.; BERNOUX, M. Carbono total e atributos químicos com diferentes usos do solo no Cerrado. Acta Scientiarum. Agronomy, v.31, p.709-717, 2009.

SOHI, S.P.; MAHIEU, N.; ARAH, J.R.M.; POWLSON, D.S.; MADARI, B.; GAUNT, J.L. A procedure for isolating soil organic 
matter fractions suitable for modeling. Soil Science Society of America Journal, v.65, p.1121-1128, 2001.

VALÉRIO, J.R. Cupins-de-montículo em pastagens. Campo Grande: Embrapa Gado de Corte, 2006. 33p. (Embrapa Gado de Corte. Documentos, 160).

VANCE, E.D.; BROOKES, P.C.; JENKINSON, D.S. An extraction method for measuring soil microbial biomass C. Soil Biology and Biochemistry, v.19, p.703-707, 1987.
VILELA, L.; SOARES, W.V.; SOUSA, D.M.G. de; MACEDO, M.C.M. Calagem e adubação para pastagens na região do Cerrado. Planaltina: Embrapa-CPAC, 1998. 16p. (Embrapa-CPAC. Circular técnica, 37).

WARING, S.A.; BREMNER, J.M. Ammonium production in soil under waterlogged conditions as an index of nitrogen availability. Nature, v.201, p.951-952, 1964.

Recebido em 16 de março de 2011 e aprovado em 22 de novembro de 2011 